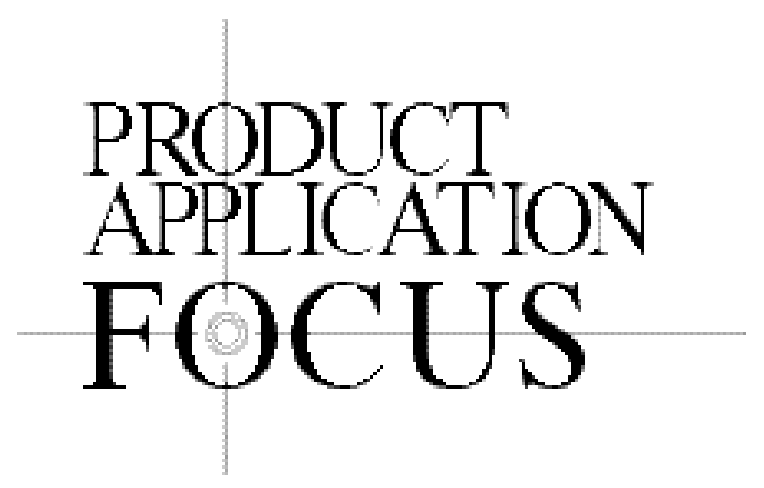

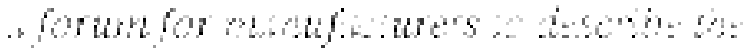

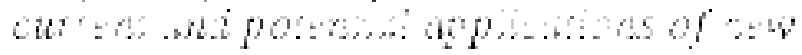

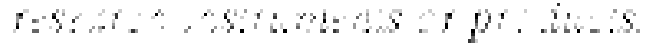

\title{
Serum-Free Recombinant Production of Adenovirus Using a Hollow Fiber Capillary System
}

\author{
T.A. Gardner',2, S.-C. Ko ${ }^{1}$, L. Yang ${ }^{1}$, J.J.S. Cadwell ${ }^{3}$, L.W.K. Chung ${ }^{1}$, and C. Kao ${ }^{1,2}$ \\ ${ }^{1}$ University of Virginia Health Sciences Center, Charlottesville, VA, ${ }^{2}$ Indiana University \\ Medical Center, Indianapolis, IN, and ${ }^{3}$ FiberCell Systems, New Market, MD, USA
}

BioTechniques 30:422-427 (February 2001)

\begin{abstract}
A novel method for the production of adenoviral vectors on a scale sufficient to support most research applications and early phase clinical trials is presented. This method utilizes serum-free cell culture medium and a hollow fiber cell culture apparatus. Significantly less time and space are required than in conventional methods, and the resulting adenovirus is collected in a much smaller volume, simplifying the purification steps. The protocol described is a reproducible, convenient, biologically safe, and environmentally sound method for the production of adenoviral vectors for laboratory use and has the potential to scale-up the adenovirus production for clinical use.
\end{abstract}

\section{INTRODUCTION}

Adenoviral vectors are being used increasingly for gene therapeutics to treat genetic diseases and cancer (2). Current laboratory and clinical adenoviral vector production techniques use multiple flasks, liquid culture (4), or a bioreactor culture system (3). These techniques for producing recombinant adenoviral vectors require significant man-hours, additional safety testing of serum additives, generate significant biological waste (4), and require special equipment that is not readily available to most laboratories. In an attempt to simplify the production technique, remove the serum additives, and minimize production of biological waste, we have developed a method using an artificial capillary cell culture system in conjunction with a serum-free medium designed to adapt the 293 cell line used in the production of adenoviral vectors to suspension culture. Under these conditions, large numbers of cells (up to $1 \times 10^{9}$ total) can be grown in a small volume (approximately $10 \mathrm{~mL}$ ) in which efficient viral infections can be observed. The infection cycle takes place entirely in the closed environment of the hollow fiber module, and recombinant adenoviral vector harvesting can be simply accomplished in a matter of a few minutes and is in a concentrated volume of $30 \mathrm{~mL}$ or less.

This paper will describe the techniques used in the production of recombinant adenoviral vectors using an artificial hollow fiber capillary cell culture system in serum-free medium. We have compared the results with the conventional plastic flask production frequently performed by our laboratory. The techniques developed for producing adenoviral vectors in the capillary system allow the generation of high-titer viruses in the absence of serum with much reduced preparation time and biological waste. This technology could be potentially further developed for large-scale production of adenoviral vectors and other viral vectors for clinical applications.

\section{MATERIALS AND METHODS}

\section{Generation of 293 Cells for Suspension Culture and Expansion of Suspension of 293 Cells under Serum-Free Condition}

293 cells were adapted to suspension cell culture according to Irvine Scientific (Santa Ana, CA, USA). Once the cells were in suspension, the cells were diluted in IS 293 medium to a concentration of approximately $5 \times 10^{5}$ cells $/ \mathrm{mL}$. These 
cells are then distributed in suspension to culture vessels and incubated at $37^{\circ} \mathrm{C}$, starting at an adequate speed to keep the cells from settling or clumping. When cell densities reached $2 \times 10^{6}$ cells $/ \mathrm{mL}$ (about three days), they were diluted to approximately three- to fourfold and distributed to larger culture vessels. Passages can be made with a 1:10 split per week or 1:3 split every three days. All cell cultures were performed using IS 293 media (Irvine Scientific). This medium was supplemented with $10 \mu \mathrm{g} / \mathrm{mL}$ sodium heparin (Sigma, St. Louis, MO, USA) and $0.1 \%$ Plueronic F-68 solution (Sigma) to maintain optimal suspension culture condition.

\section{Artificial Capillary Cell Culture}

The Cellco Cellmax ${ }^{\mathrm{TM}}$ (Spectrum, Rancho Dominguez, CA, USA) artificial capillary cell culture system with the 30 kd MWCO cellulosic fiber module (Cellco 400-011) was found to have the best characteristics for growth of suspension 293 cells and adenovirus production. The cells were cultured on the outside of the fiber in the extra-capillary space (ECS), while medium was recirculated through the inside of the fibers. Low molecular weight components such as glucose, lactate, and amino acids are free to pass through the fiber, while larger molecules, viruses and cells, are completely retained in the ECS by the fiber. The adenovirus did not pass through the fiber, as confirmed by assays performed in this laboratory (data not shown). The surface area available in this cartridge is $2200 \mathrm{~cm}^{2}$, permitting the culture of 293 cells at high densities of approximately $10^{8}$ cells $/ \mathrm{mL}$. The Cellmax System consists of a cartridge with flow path, pump, and medium reservoir. The flow path contains 8-16 feet of silicone tubing through which gas exchange takes place while the medium is flowing through the system.

\section{Conventional Viral Production in T175 Flasks}

Adherent 293 cells were cultured in minimum essential medium (MEM) with 10\% FBS and propagated in a 1:5 fashion in P100 dishes. For viral production, cells from one confluent P100 dish were transferred to one T175 flask. A pre-infection was performed using 5-10 multiplicity of infection (MOI) of adenovirus in a confluent T175 flask of 293 cells, and that flask was then harvested 36-48 h after infection when a cytopathic effect (CPE) was realized. The cells were then tapped off the flask, and the media containing these cells were harvested. The cells were spun down with a clinical centrifuge, resuspended with $2 \mathrm{~mL}$ PBS, and subjected to three rounds of freeze-thaw. The cell debris was spun down and removed, and $0.1 \mathrm{~mL}$ of the supernatant was then applied to one T175 flask of 293 cells, about $90 \%$ confluence at the time of the adenoviral infection. Approximately $36-48 \mathrm{~h}$ after this infection, a substantial CPE was realized, and these cells were then harvested. We used the methods described by Graham and Prevec (5) for virus purification and titering. 


\section{Capillary Cell Culture System Production of Adenovirus}

Serum-free suspension 293 cells were maintained in liquid culture with a spinner flask culture system. The liquid culture can be started directly from a liquid nitrogen frozen vial (containing $5 \times 10^{7}$ cells). The cells can be propagated through three- to fourfold dilution every three days and maintained in $500-$ or $1000-\mathrm{mL}$ stir bottles depending on the quantity of cells required. These cells, when adequate numbers are obtained, can be used to inoculate the artificial capillary cell culture system. Cells were spun down, resuspended in $15 \mathrm{~mL}$ medium, split into two $10-\mathrm{mL}$ syringes, and then inoculated into the pre-equilibrated hollow fiber ECS, as described by the manufacturer's protocol. It takes 15 min to perform the whole process of cell inoculation.

Three different recombinant adenovirus production techniques are described below. The first was to inoculate approximately $5 \times 10^{7}$ cells on day 0 , after allowing the cartridge to equilibrate. These cells were then allowed to grow within the cartridge until day 5 . The growth of cells was monitored by the increase in lactate production, which correlated very well with cell number (Figure 1, a and b). The ECS on day 5 contained approximately $5 \times 10^{8}$ cells, which were infected with 5-10 MOI of recombinant adenovirus by directly injecting the virus into the chamber and mixing well with medium within the ECS using 10-mL syringes. Subsequently, the cells were harvested at a point when the lactate production fell, which occurred approximately on day 8 or $72 \mathrm{~h}$ after the virus inoculation (Figure 2a). The second approach was to inoculate the capillary system with $5 \times 10^{8}$ cells and allow the cells to equilibrate for $24 \mathrm{~h}$. An infection with 5-10 MOI of recom binant adenovirus was then carried out as described above. The viral particles produced were harvested approximately after $72 \mathrm{~h}$ (Figure 2b). The third technique was to co-inoculate the cells starting between $5-10 \times 10^{8}$ cells with $5-10$ MOI of recombinant adenovirus. This co-inoculated capillary system was harvested approximately three days after setting up the capillary system (Figure 2c). In each technique employed, the extra-capillary volume of approximately $12 \mathrm{~mL}$ was harvested with a $10-\mathrm{mL}$ syringe, and the ECS was rinsed with $24 \mathrm{~mL}$ phosphate buffer. This $36 \mathrm{~mL}$ final product was convenient for cesium chloride banding as described (5).

\section{RESULTS}

Serum-free 293 cells adapted to suspension growth were cultured in a sterile spinner flask. Since it is difficult to directly count the cells in the hollow fiber system, we explored the use of lactate production rate as an indicator of cell number in this study. Lactate production presented in Figure 1a was displayed as milligrams of lactate produced per day. Corresponding cell numbers were depicted in Figure 1b. Upon generating enough suspension 293 cells, the cells were spun down and inoculated into a capillary system in a range of $8.5 \times 10^{7}$ or $2.0 \times$ $10^{9}$ cells at initial inoculation. Using the various seeding techniques described above in Materials and Methods, Figure 2 demonstrated the lactate production before and after adenoviral infection using various growth conditions. The lactate production for capillary systems, which is demonstrated in Figure 2 , showed a peak production followed by a sharp falloff associated with the generation of an adenoviral burst. Harvest at this time was designed to allow for maximum production of biologically active recombinant adenoviral vectors. Further incubation did not improve the yield (unpublished observation). We did not observe significant differences in the virus yield between these three methods. The advantage of culturing the cells in the cartridge is that cells can be inoculated directly into the hollow fiber cartridge from the thawed vial without going through the spinner culture step. This is particularly useful when the system is scaled up for a large quantity of adenovirus production. It takes less than 5 min to perform the medium change, and the part of the culture system containing the aden-

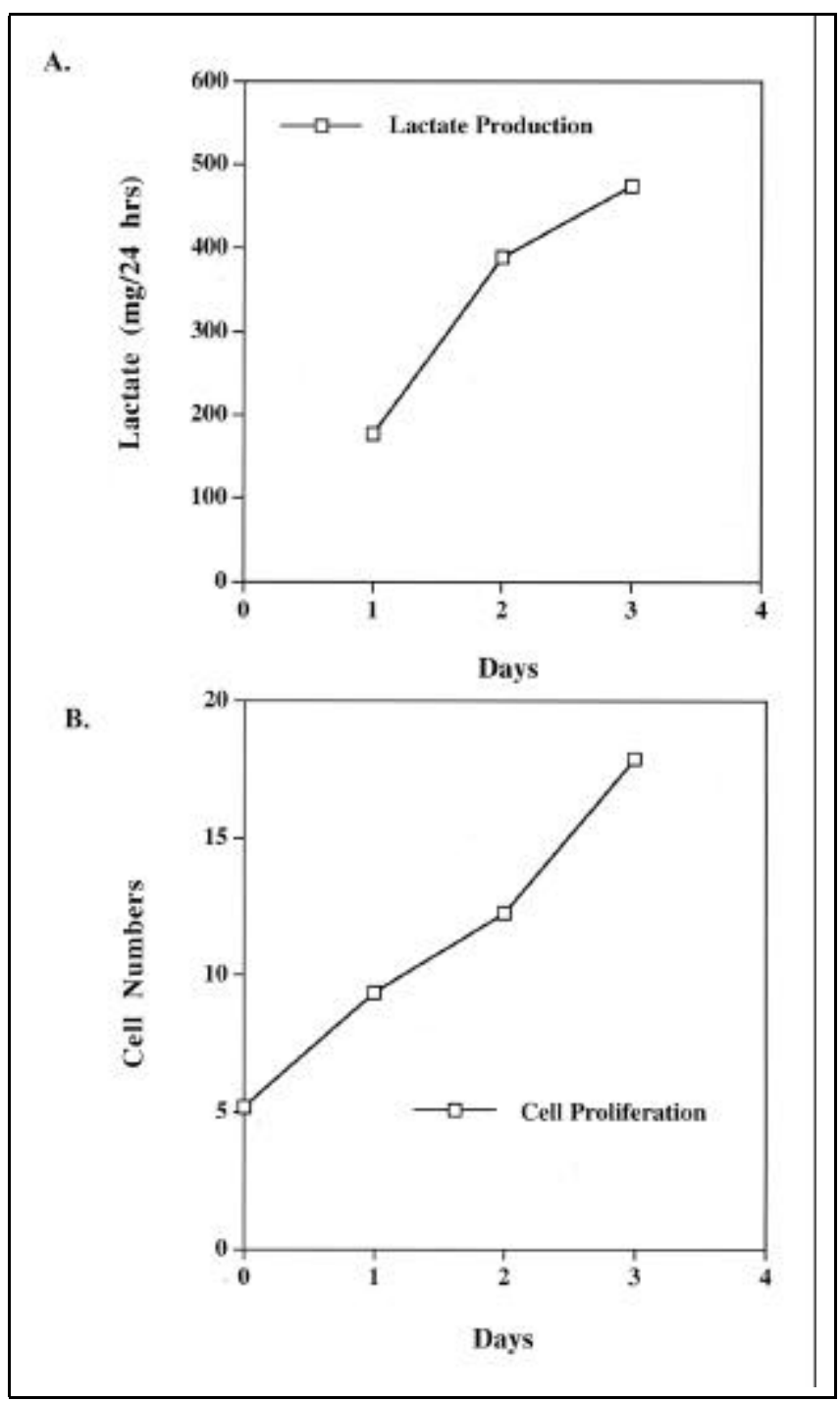

Figure 1. Adenovirus production in hollow fiber system. (a) 293 cells were cultured in the capillary system, starting out with $6.6 \times 10^{7}$ cells inoculated on day 0 . On day 5, 293 cells grew to approximately $5 \times 10^{8}$ cells and were infected with 5-10 MOI of adenovirus. The lactate production rate continued to rise for approximately one more day and went down. On day 8, after the initial inoculation or $72 \mathrm{~h}$ after the viral inoculation, the cells were harvested. (b) Cells accrued within the capillary system and were infected on the second day after inoculation of the cells. In this particular case, $5 \times 10^{8}$ cells were seeded in the capillary system and subsequently infected with 5-10 MOI of recombinant adenovirus, then harvested on day 4 . The pattern of lactate production rate after virus infection is similar to panel a. (c) A third production technique that allows for a co-inoculation of $8.45 \times 10^{8}$ suspension cells with 5 MOI of recombinant and a subsequent harvest after the fall of lactate production. This graph represents an accumulative lactate production, in contrast to the other graphs. On day 3 , a fall in lactate production suggests significant production of the adenovirus. 
Table 1. Comparison of New Technique to Conventional Virus Production

\begin{tabular}{|c|c|c|c|}
\hline & $\begin{array}{l}\text { Old Technique } \\
\text { (200 T175s) }\end{array}$ & $\begin{array}{c}\text { New Technique } \\
\text { (4 Cartridges) }\end{array}$ & $\begin{array}{l}\text { Comparison } \\
\text { (Old:New) }\end{array}$ \\
\hline \multicolumn{4}{|l|}{ Waste } \\
\hline Biological Hazards & $27500 \mathrm{in}^{3}$ & $360 \mathrm{in}^{3}$ & $75: 1$ \\
\hline \multicolumn{4}{|l|}{ Storage space } \\
\hline Plasticware & $23222 \mathrm{in}^{3}$ & $360 \mathrm{in}^{3}$ & $65: 1$ \\
\hline \multicolumn{4}{|l|}{ Incubators } \\
\hline Number & 5 & 1 & $5: 1$ \\
\hline \multicolumn{4}{|c|}{ Person-hours (one experienced technician) } \\
\hline Preparation of 293 cells & $\begin{array}{c}8 \mathrm{~h} \\
\text { (preparing } 200 \mathrm{p} 100 \text { dishes) }\end{array}$ & $\begin{array}{c}1 \mathrm{~h} \\
\text { (preparing } 1 \mathrm{~L} \text { liquid culture) }\end{array}$ & \\
\hline Media change & $\begin{array}{c}12 \mathrm{~h} \\
(4 \mathrm{~h} / \text { change } \times 3)\end{array}$ & $\begin{array}{c}0.33 \mathrm{~h} \\
(1 \text { change })\end{array}$ & \\
\hline Seeding cells for production & $\begin{array}{c}12 \mathrm{~h} \\
\text { (preparing } 200 \mathrm{T175s} \text { ) }\end{array}$ & $\begin{array}{c}1 \mathrm{~h} \\
\text { (preparing } 4 \text { cartridges) }\end{array}$ & \\
\hline $\begin{array}{l}\text { Media change and } \\
\text { virus inoculation }\end{array}$ & $\begin{array}{c}12 \mathrm{~h} \\
\text { (preparing } 200 \mathrm{T175s} \text { ) }\end{array}$ & $\begin{array}{c}1 \mathrm{~h} \\
\text { (preparing } 4 \text { cartridges) }\end{array}$ & \\
\hline Harvest of cells & $\underline{8 \mathrm{hr}}$ & $1.66 \mathrm{~h}$ & \\
\hline Total Hours & $55 \mathrm{~h}$ & $6 \mathrm{~h}$ & $9: 1$ \\
\hline \multicolumn{4}{|l|}{ Supplies (\$) } \\
\hline Plasticware & $\$ 900$ & $\$ 1200$ & \\
\hline Media & $\$ 200$ & $\$ 480$ & \\
\hline Serum & $\$ 600$ & $\$ 0$ & \\
\hline Totals & $\$ 1700$ & $\$ 1680$ & $1: 1$ \\
\hline \multicolumn{4}{|c|}{ Adenovirus produced after CsCl purification (virus particles) } \\
\hline & $2.4 \times 10^{13}$ v.p. & $2.4 \times 10^{13}$ v.p. & $1: 1$ \\
\hline
\end{tabular}

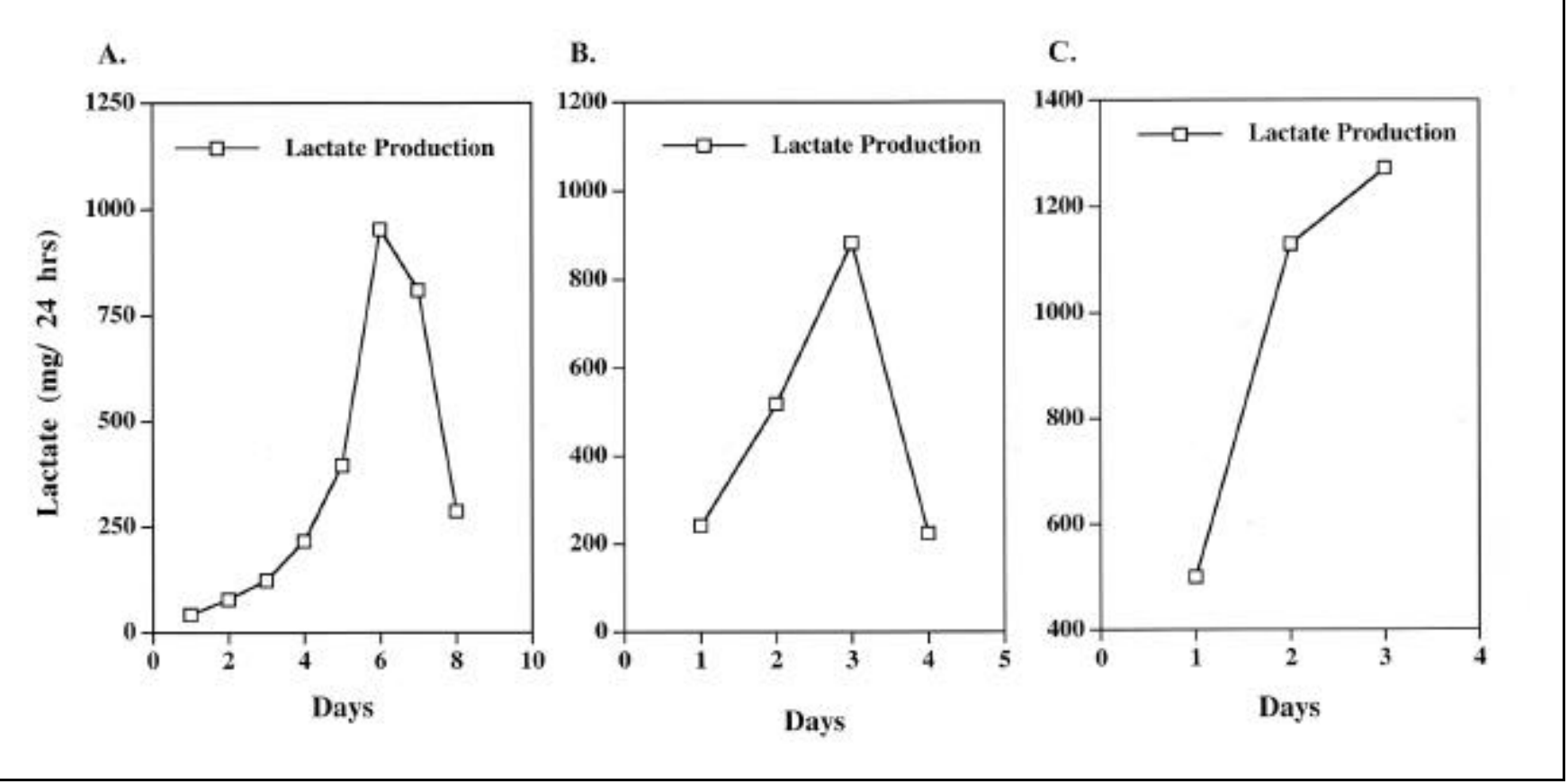

Figure 2. The growth of 293 cells in spinner culture. 293 cells grew very well in 293 IS serum-free medium in spinner bottle. Lactate production (mg/day) by the cells increases in a logarithmic fashion (a) that parallels to cell numbers (b). This character allows us to use lactate production as an indicator of cell number. The cells could grow to a density of $2.5 \times 10^{6}$ cells $/ \mathrm{mL}$. The cell doubling time is about $36 \mathrm{~h}$. 
ovirus is never opened until harvest. We did not see a benefit with the method of infecting cells one day after inoculation. We routinely used the third method (co-inoculation of cells and virus), as it was possible to re-inoculate a new batch of cells and virus directly after harvesting the previous virus production run. High-density cell stocks could be maintained in a separate hollow fiber cartridge. We were able to use the same cartridge for at least four cycles of virus production.

We have used this technology to produce 14 different recombinant adenoviruses. Each of the production techniques leads to similar viral particle yields for each particular virus and parallels the yields of conventional production techniques at $50 \mathrm{~T} 175 \mathrm{~s}$ per one hollow fiber cartridge. The virus produced with hollow fiber system was as infectious as the one produced with traditional stationary culture method as analyzed by reporter assay ( $\beta$-galactosidase or thymidine kinase assay) and plaque-forming assay. In a series of greater than 50 production runs, we have only experienced four bacterial contaminations of the hollow fiber capillary system, with the majority of these occurring during the initial development of this technique. Additionally, no adenovirus was detected in the media of the capillary system reservoir at any time during or after the production run.

Based on the cumulated experience of this laboratory with several years of conventional adenoviral production and 18 months of capillary system production, Table 1 compares the different aspects of the two techniques.

\section{DISCUSSION}

Serum-free 293 cells grown in suspension in an artificial capillary cell culture system constitutes an easy, simple, serum-free adenovirus production system that requires minimal effort and generates minimal biological waste. Several variations of the production technique have been developed that are appropriate for different timings of the production run and different amounts of suspension 293 cells. This type of production allows a greater degree of flexibility in scheduling production runs in a busy laboratory setting and may allow for similar flexibility in clinical production runs. Another advantage of using hollow fiber system is that this system retains the released virus in the small volume of the ECS and allows us to harvest the virus after the majority of the cells are lysed. Careful monitoring of the maturation status of the culture is not required; the infection is allowed to proceed to completion. The high cell density of the target 293 cells may also result in more rapid and reproducible infection kinetics.

Liquid culture of 293 cells in spinner flasks is another way to produce adenovirus. Graham et al. (5) routinely use 293 cells liquid culture method for virus production, but their cell density is very low $\left(2-4 \times 10^{5}\right.$ cells $\left./ \mathrm{mL}\right)$ and not suitable for largescale production. We had difficulty using the same methodology with serum-free medium-cultured 293 cells at a cell density of $2 \times 10^{6}$ cells $/ \mathrm{mL}$. It was difficult to determine the optimum harvesting point, and frequently the cells were harvested prematurely or too late. Either way the yield of virus was decreased. Iyer et al. (6) reported the use of 293 cell serum-free liquid culture for adenovirus production. Even with small stirred vessel bioreactor system, half of their experiments produced only one-fifth of virus compared to stationary culture method. Specifically, the author sampled the virus production at both day 2 and 3 to obtain the best yield. In practice this is difficult to perform. In addition, the collection and handling of 1-2 L cell suspension can be cumbersome, especially if all you have on hand is a clinical centrifuge for tissue culture. This problem will be even worse when production is up scaled to 10 L or more. As illustrated in Figure 2a, we can culture 293 cells in the hollow fiber for virus infection in a volume of $10 \mathrm{~mL}$ with the harvest volume being no greater than $30 \mathrm{~mL}$ so that a small clinical centrifuge, generally readily available, is sufficient for hollow fiber virus production.

Comparison of the capillary and the conventional production techniques revealed both important similarities and differences. The comparison shown in Table 1 is based on the similar viral particle yields of a 200 T175 flask run and four hollow fiber cartridges. A comparison demonstrated that each of these techniques required approximately the same cost for supplies but was vastly different in its cost analysis if personnel expenses, space, production facility size, biological waste generation, and the cost of supplies of the capillary system were included. The inexpensive plastic ware when added to the serum costs approximately equals the total cost.

Future work with this system will optimize the conditions for adenovirus production in the smaller cartridge used for this report. New serum-free cell culture media and 293 cells specifically intended for suspension culture are now available. Scale-up protocols for use in a cartridge 10 times the size of the one used in this report are also under development. The system has been well established and used for antibody and retrovirus production $(1,7)$. The potential for using this method for other virus types is also being investigated.

\section{ACKNOWLEDGMENTS}

Irvine Scientific provided a portion of the 293 IS media used in production of adenoviral vectors and Spectrum CELLCO provided the CellMax system with a variety of cartridges that were tested. The authors also wish to thank Sarajiki Pierson and Gary Mawyer for assistance in the preparation of this manuscript.

\section{REFERENCES}

1.Pan, D., R. Shankar, D.F. Stroncek, and C. Whitley. 1999. Combined ultrafiltration-transduction in a hollow-fiber bioreactor facilitates retrovirusmediated gene transfer into peripheral blood lymphocytes from patients with mucopolysaccharidosis type II. Hum. Gene Ther. 10:2799-2810.

2.Gardner, T.A., S.-C. Ko, C. Kao, T. Shirakawa, J. Cheon, A. Gotoh, T.T. Wu, R.A. Sikes et al. 1998. Exploiting stromal-epithelial interaction for model development and new strategies of gene therapy for prostate cancer and osteosarcoma metastases. Gene Ther. Mol. Biol. 2:41-58.

3.Garnier, A., J. Cote, I. Nadeau, A. Kamen, and B. Massie. 1994. Scaleup of the adenovirus expression system for the production of recombinant protein in human 293S cells. Cytotechnology 15:145-155.

4.Graham, F.L. and L. Prevec. 1992. Adenovirus-based expression vectors and recombinant vaccines. Biotechnology 20:363-390.

5.Graham, F.L. and L. Prevec. 1995. Methods for construction of adenovirus vectors. Mol. Biotechnol. 3:207-220.

6.Iyer, P., J.M. Ostrove, and D. Vacante. 1999. Comparison of manufacturing techniques for adenovirus production. Cytotechnology 30:169-172.

7.Beck T., L. Shuch, S. Sitlani, and M. Menaker. 1994. Monoclonal antibody production in an artificial capillary cell culture system. Focus 17:2-5.

Address correspondence to Dr. Chinghai Kao, Associate Professor, Department of Urology, Indiana Cancer Pavilion, 535 N. Barnhill Dr., Suite 420, Indianapolis, IN 46202-5289, USA.e-mail:chkao@iupui.edu 